Int. J. Dev. Biol. 61: 43-52 (2017)

doi: $10.1387 / \mathrm{ijdb} .160169 \mathrm{rb}$

\title{
The natural compound sanguinarine perturbs the regenerative capabilities of planarians
}

\author{
LINDA BALESTRINI,"\#, ALESSIA DI DONFRANCESCO ${ }^{1, \#, ~ L E O N A R D O ~ R O S S I ~}{ }^{2}$, SILVIA MARRACCI ${ }^{1}$, \\ MARIA E. ISOLANI' ${ }^{3}$, ANNA M. BIANUCCl${ }^{4}$ and RENATA BATISTONI*,1,5

\begin{abstract}
${ }^{1}$ Dipartimento di Biologia, Università di Pisa, ${ }^{2}$ Dipartimento di Medicina Clinica e Sperimentale, Università di Pisa, ${ }^{3}$ Dipartimento di Farmacia, Università di Pisa, Pisa, Italy, ${ }^{4}$ Istituto Nazionale per la Scienza e Tecnologia dei Materiali, Florence and ${ }^{5}$ Interdepartmental Research Center "Nutraceuticals and Food for Health" University of Pisa, Pisa, Italy
\end{abstract}

\begin{abstract}
The natural alkaloid sanguinarine has remarkable therapeutic properties and has been used for centuries as a folk remedy. This compound exhibits interesting anticancer properties and is currently receiving attention as a potential chemotherapeutic agent. Nevertheless, limited information exists regarding its safety for developing organisms. Planarians are an animal model known for their extraordinary stem cell-based regenerative capabilities and are increasingly used for toxicological and pharmacological studies. Here, we report that sanguinarine, at micromolar concentrations, perturbs the regeneration process in the planarian Dugesia japonica. We show that sanguinarine exposure causes defects during anterior regeneration and visual system recovery, as well as anomalous remodelling of pre-existing structures. Investigating the effects of sanguinarine on stem cells, we found that sanguinarine perturbs the transcriptional profile of early and late stem cell progeny markers. Our results indicate that sanguinarine exposure alters cell dynamics and induces apoptosis without affecting cell proliferation. Finally, sanguinarine exposure influences the expression level of $\mathrm{H}^{+}, \mathrm{K}^{+}$-ATPase $\alpha$ subunit, a gene of the P-type-ATPase pump family which plays a crucial role during anterior regeneration in planaria. On the whole, our data reveal that sanguinarine perturbs multiple mechanisms which regulate regeneration dynamics and contribute to a better understanding of the safety profile of this alkaloid in developing organisms.
\end{abstract}

KEY WORDS: regeneration, planarian, gene expression, sanguinarine, developmental toxicology

\section{Introduction}

In recent years free-living flatworms (planaria) have emerged as a remarkable model in the modern study of regeneration. The amazing regenerative capabilities of planarians depend on the presence of a large pool of adult stem cells (neoblasts), at least some of which are pluripotent. Neoblasts are widely distributed throughout the body and are the only dividing cells in planarians. Thought to be a heterogeneous population, these cells are able to replace all differentiated cells during homeostasis and are recruited to initiate regeneration after wounding. Regeneration initiates with wound healing and is followed by increased neoblast proliferation at the injury site. An outgrowth of non-dividing progeny cells, morphologically identifiable as an unpigmented tissue (the regenerative blastema), is rapidly formed in the damaged site to regenerate the missing body parts, while morphallactic remodelling adjusts the size of the remaining fragment. As a result a new smaller worm with all the parts adjusted to the new proportions is quickly formed. Given the wealth of molecular tools that are now available, the stem cell-based regenerative biology of planarians has been extensively explored, providing valuable insights into the principles and mechanisms of tissue and organ regeneration (Salò et al., 2009; Elliot and Sànchez Alvarado, 2013). Activation of apoptotic cell death and different signalling mechanisms, including gradients of morphogens, bioelectrical signals and gap-junctional communications (Nogi and Levin, 2005; Beane et al., 2011) orchestrate this process and ensure restoring of the correct morphology

Abbreviations used in this paper: Sang, sanguinarine

\footnotetext{
*Address correspondence to: Renata Batistoni. Dipartimento di Biologia, Università di Pisa, S.S. Abetone e Brennero 4, 56126, Pisa, Italy.

E-mail: renata.batistoni@ unipi.it iD http://orcid.org/0000-0001-8689-708X - \#Note: Both authors contributed equally to this paper
}

Supplementary Material (two figures + one table) for this paper is available at: http://dx.doi.org/10.1387/ijdb.160169rb

Submitted: 24 May, 2016; Accepted: 12 December, 2016.

ISSN: Online 1696-3547, Print 0214-6282

(C) 2017 UPV/EHU Press

Printed in Spain 
of the planarian body. Planarians display bilateral symmetry and cephalization. Despite the simple external shape of these animals, their tissues and organs, including the nervous system, possess structural and molecular complexity and fulfil complex metabolic functions similar to those of mammals. Altogether, planarians are inexpensive, easy to reproduce in the laboratory as genetically identical individuals and amenable to genetic manipulation by modern research tools. These unique features make planarians a valuable in vivo model for developmental toxicity and pharmaceutics research. In vivo toxicological studies on classical multicellular non-vertebrate model systems, such as Drosophila melanogaster or Caenorhabditis elegansor non-mammalian vertebrates, provide information about drug interaction in complex molecular pathways and during embryonic development, but they do not offer opportunity to analyze effects on stem cells. Planarian regeneration represents a unique context in which toxicological effects on stem cells can be mechanistically investigated (Hagstrom etal., 2016 and references therein). To date, the high sensitivity to chemicals of this simple animal model seems to be promising to investigate the effects of toxicants on different conserved signaling pathways, providing exciting new clues to speculate on specific and complex mechanisms underlying different human diseases (Raffa and Rawl, 2008).

Sanguinarine is a bioactive alkaloid found in several plants of the Papaveraceae family. This compound is mainly known for its antibacterial, anti-fungal and anti-inflammatory potential (Gupta et al., 2010). Due to its antibacterial properties sanguinarine has been utilized in dental hygiene products to repress the growth of dental plaque. On the other hand, other studies report concerns of toxicity linked to increased risks of oral leukoplakia, questioning safety of the use of this compound in dental care products (Maskarenhas et al., 2002). Sanguinarine also appears to exert interesting anticancer activities, playing a crucial role in various steps of tumor cell development and metastases (Gaziano et al., 2016). Furthermore, this compound has been incorporated into food additives to promote animal growth, exhibiting properties that
A

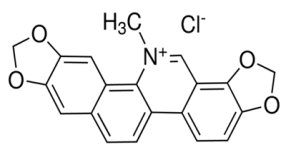

B

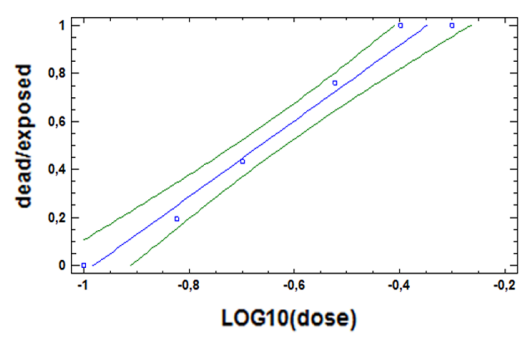

Fig. 1. Toxicity of sanguinarine on planarians. (A) Chemical structure of sanguinarine. (B) The linear regression graph shows the mean mortality of exposed animals plotted against the values of LOG10 (dose of sanguinarine administered by soaking). The equation of the fitted model is dead/ exposed $=1,5457+1,57278 *$ LOG10(dose). Since the P-value calculated by ANOVA method is less than 0.05 there is a statistically significant relationship between dead/exposed and LOG10(dose) at the 95,0\% confidence level. The R-Squared statistic indicates that the model as fitted explains $98,1753 \%$ of the variability in dead/exposed animals. The correlation coefficient equals 0,990834, indicating a relatively strong relationship between the variables. Green lines represent the 95,0\% confidence intervals of the linear regression line (blue). For each condition, 3 independent experiments were performed with 10 planarians of $5 \mathrm{~mm}$ in length. are of veterinary relevance (Kosina et al., 2004). Sanguinarine has remarkable effects against helminth and protozoan parasites of fish (Yao et al., 2010) and it has been proposed as a drug alternative to praziquantel for treatment of schistosomiasis, a disease caused by parasitic flatworms (Zhang and Coultas, 2013).

Although a number of literature data underlines the promising therapeutic importance of sanguinarine (Gaziano et al., 2016), there is only limited information about the effects of this alkaloid during embryonic development (Chan, 2014). Application of these results to clinical practice requires further in vivo studies to define its possible effects on developing organisms.

In this study, we use the planarian Dugesia japonica as a suitable non-mammalian model to investigate the potential adverse effects of sanguinarine on regeneration. Our study reports that sanguinarine has multiple effects on planarian regeneration. The exposure to a micromolar concentration of this alkaloid causes abnormal anterior regeneration and obvious defects during visual system recovery, as well as anomalous remodelling of pre-existing structures. Based on these results, we conclude that sanguinarine produces developmental effects and alters the normal regeneration process of planarians. Identify the mechanisms by which sanguinarine acts in the context of whole-body dynamics can provide valuable implications to evaluate the safe use of this alkaloid in various therapeutic areas.

\section{Results}

\section{Toxicity of sanguinarine in planarians}

The chemical structure of sanguinarine is shown in Fig. 1A. In order to determine the range of concentration within which sanguinarine exposure affected planarian regeneration, a series of dilutions $(0.1 \mu \mathrm{M} ; 0.15 \mu \mathrm{M} ; 0.2 \mu \mathrm{M} ; 0.3 \mu \mathrm{M} ; 0.4 \mu \mathrm{M} ; 0.5 \mu \mathrm{M} ; 0.7 \mu \mathrm{M}$; $0.9 \mu \mathrm{M} ; 1.1 \mu \mathrm{M})$ were prepared in planarian water. Animals were monitored every day, checking their condition (death/no death), in order to determine the smallest tolerated dose (100\% mortality) and the highest tolerated dose ( $0 \%$ mortality). Once these two doses were determined, 4 doses in between were selected, and the mortality due to these doses was assayed. Seven days have been selected as reference time point because at that time a planarian fragment has reformed principal organs. After 7 days of treatment, the highest mortality (100\%) was observed at $0.5 \mu \mathrm{M}$ sanguinarine. The linear regression graph (Fig. 1B) shows the mean mortality of exposed animals plotted against the values of LOG10 of increasing doses of sanguinarine. Based on linear regression equation the LC50 and LC95 values were calculated as $0.21 \mu \mathrm{M}$ and $0.41 \mu \mathrm{M}$, respectively. We chose $0.15 \mu \mathrm{M}$ sanguinarine - a concentration corresponding to $20 \%$ of mortality - as working solution for the experiments. This working solution corresponds to $0.015 \%$ DMSO, a solvent concentration that does not significantly interfere with cell proliferation or motility/behavior of planarians (Pagán et al., 2006; Isolani et al., 2012; Yuan et al., 2012; Stevens et al., 2015).

\section{Vital epifluorescence imaging of sanguinarine distribution in planarians}

Sanguinarine exhibits intrinsic red fluorescence under 510$560 \mathrm{~nm}$ light. After soaking in sanguinarine, its presence and distribution in living planarians was visualized by an epifluorescence microscope. In intact planarians the alkaloid appeared widely distributed in the body, and occasionally was found accumulated 
in the intestine. Some accumulation of red signal was also observable in the head, the most sensitive body region to the effects of the alkaloid. Distribution of sanguinarine did not differ significantly in regenerating animals (Supplementary Fig. 1).

\section{Sanguinarine affects anterior regeneration}

After planarian bisection at the prepharyngeal level, morphometric analysis of the ratio between the regenerative blastema and the stump area provided quantitative evidence that, following sanguinarine exposure, head fragments regenerated a tail without defects, while tail fragments regenerated a head that was anomalous in shape and size (45/80) (Fig. 2 A,B). Phenotypes with different level of severity were observed (Fig. 2A). The most severe phenotypes were fragments devoid of blastema (25/80), resulting in headless planarians. The anomalous anterior regeneration in sanguinarine-treated planarians did not depend on the level of amputation along the anterior-posterior (AP) axis. In fact when planarians were cut into three pieces (head, trunk and tail), both head and trunk fragments regenerated a posterior blastema that was comparable to the controls (60/60). In contrast the anterior blastema of trunks and tails was significantly reduced in size or its formation did not occur (55/60) (Fig. 2C). Moreover, when the animals were longitudinally amputated in presence of sanguinarine, they regenerated an asymmetric lateral blastema, i.e. the blastema area gradually increased in size along the AP axis (30/30) (Fig. 2D). The evidence that sanguinarine selectively affects anterior regeneration was also provided by anti-arrestin immunostaining (VC-1 antibody) showing anomalous regeneration of the visual system (Fig. 3A). In situ hybridization with the pan-neural marker Dj-syt (Salvetti et al., 2000) also demonstrated that sanguinarine impaired regeneration of the cephalic ganglia (the planarian brain) (Fig. 3B). Tail fragments with small blastemas or without any visible blastemal tissue regenerated cephalic ganglia and eyes that had anomalous anatomy and were partially or totally localized in the stump (Fig. 3A,B). Additionally, sanguinarine-treated tail fragments had the pharynx that appeared oversized and anteriorly shifted with respect to the controls (23/43). In situ hybridization with the marker of pharynx muscles (Dj-mhca: Kobayashi et al., 1998) and morphometric analysis confirmed that the failure of the pharyngeal remodelling in sanguinarine-treated animals was statistically significant (Fig. 4A,B). The possibility that sanguinarine interferes with growth and morphallactic remodelling of pre-existing tissue was also supported by the observation that morphogenesis of the intestine, visualized by Dj-inx1 (Nogi and Levin, 2005), showed abnormalities (20/30) (Fig. 4C). The abnormalities observed in the pharynx and intestine following sanguinarine treatment were
A

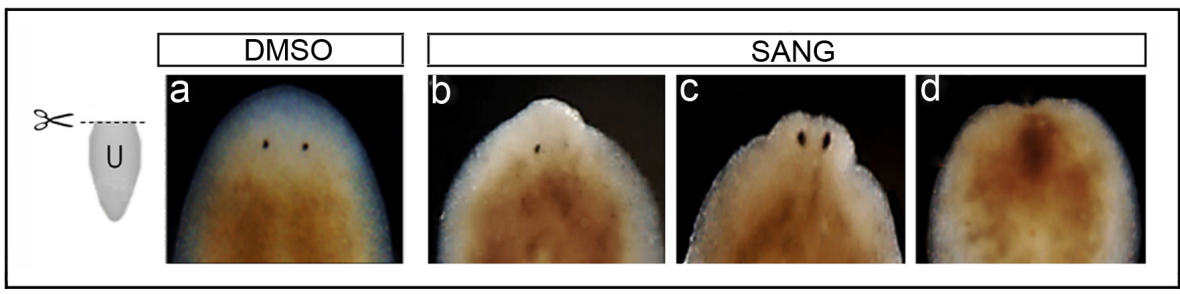

B

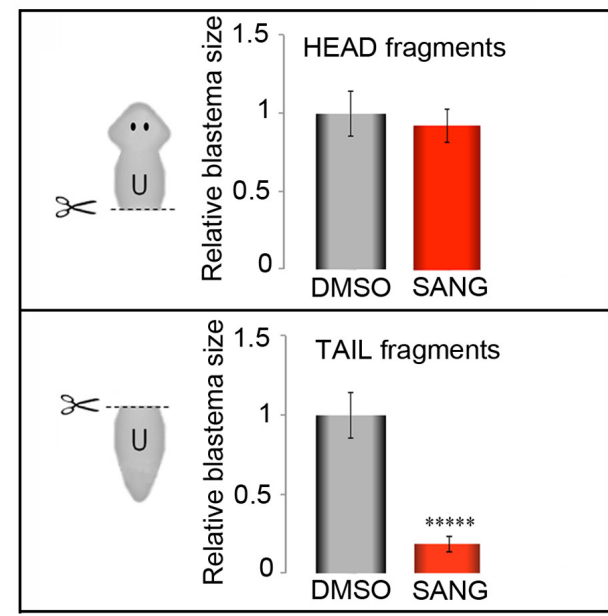

D

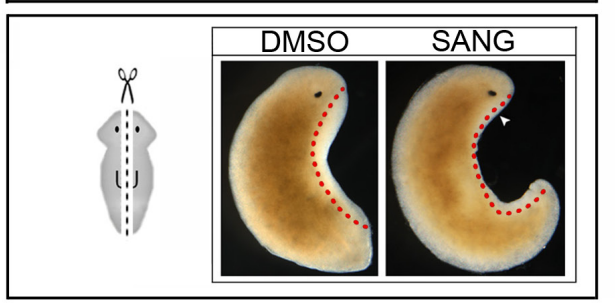

C

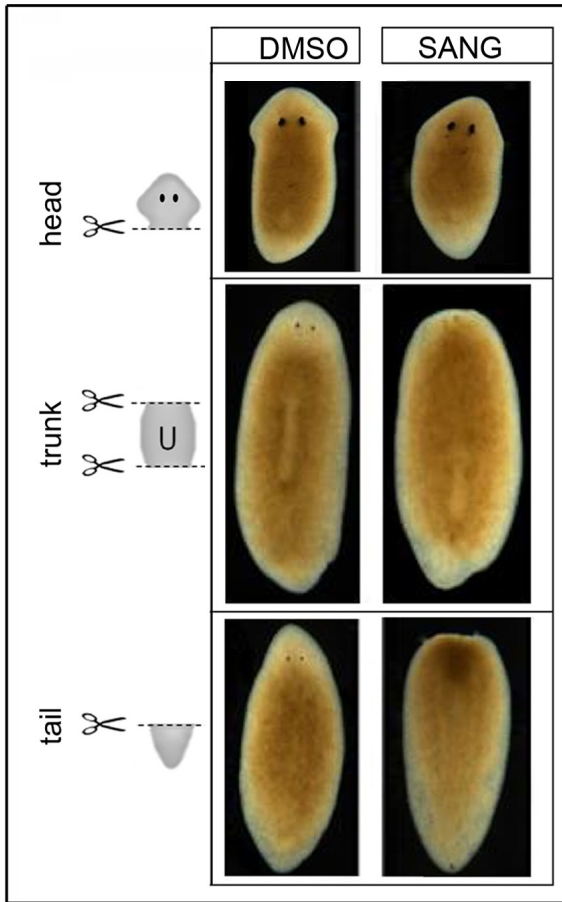

Fig. 2. Sanguinarine treatment affects anterior regeneration. (A) Representative brightfield images of sanguinarine-treated planarians and controls regenerating a head after 7 days of regeneration. Most sanguinarine-treated planarians showed phenotypes (57\%). (a) A control regenerating a normal head (100\%). $(b, c, d)$ Representative phenotypes after sanguinarine treatment. (b) Anterior blastema with anomalous shape and with one eye (16\%). (c) Anterior blastema with anomalous shape and with two eyes (9\%). (d) A severe phenotype devoid of anterior blastema and eyeless (32\%). (B) Morphometric analysis of the blastema size in head fragments and tail fragments regenerating a posterior blastema and an anterior blastema, respectively (regeneration: 7 days). Values are average \pm s.d. from 30 samples. ****: $p<0,00001$. (C) Representative brightfield images of sanguinarine-treated fragments (head, trunk, tail) and controls after 7 days of treatment (regeneration: 7 days). The anterior blastema of trunks and tails of sanguinarinetreated planarians was significantly reduced in size or its formation did not occur (90\%), while the posterior blastema of sanguinarinetreated fragments was comparable to that of controls. The percentage of anterior blastemas with one eye or two eyes was comparable to that observed when planarians were bisected at the prepharyngeal level. (D) A longitudinally amputated sanguinarine-treated planarian regenerating an asymmetric lateral blastema (white arrowhead) (100\%) with respect to the control. Broken red lines indicate the blastema area. For each experiment, 30 animals were used. Control: DMSO 0,015\%; SANG: sanguinarine $0.15 \mu \mathrm{M}$. Anterior is up. Scale bars: (C,D) $1 \mathrm{~mm}$; (A) 500 um. 
Fig. 3. Sanguinarine treatment impairs the regeneration of the visual system and cephalic ganglia. (A) Visualization of the visual system by immunostaining with VC-1 antibody (white arrows) of representative phenotypes of sanguinarinetreated planarians regenerating a head after 7 days of treatment (7 days of regeneration). (a) Visualization of the visual system in a control. All controls regenerated a normal visual system (100\%). (b) An anomalous anterior blastema with two eyes, optic chiasm is not visible. (c) An anomalous anterior blastema with two eyes localized in the stump, optic chiasm is not visible (57\%). (d) A phenotype devoid of anterior blastema and eyeless (32\%). (B) Visualization of cephalic ganglia after whole mount in situ hybridization with the pan-neural marker Dj-syt (white arrows) of representative phenotypes of sanguinarine-treated planarians regenerating a head after 7 days of treatment (7 days of regeneration). (a') Visualization of the cephalic ganglia in a control. All controls regenerated normal cephalic ganglia (100\%). (b') Cephalic ganglia with anomalous morphology and reduced size are localized in a small blastema. ( $\left.c^{\prime}\right)$ Cephalic ganglia with anomalous morphology are partially localized in the stump. (d') Cephalic ganglia with anomalous morphology and reduced size are localized in the stump. e: eye. oc: optic chiasm. cg: cephalic ganglia. For each experiment, 30 animals were used. Control: DMSO 0,015\%; SANG: sanguinarine $0.15 \mu \mathrm{M}$. Anterior is up. Scale bar: $1 \mathrm{~mm}$.

associated with functional alterations. When planarians were fed with liver coloured with red food dye the intestine of controls became red, while food could be only sporadically visualized in sanguinarine-treated animals (Fig. 4D). No alteration in intestine, protonephridia and nerve cords morphology were observed during posterior regeneration (Supplementary Fig. 2).

\section{Effects of sanguinarine on stem cells and their progeny}

The anomalous phenotypes observed following sanguinarine treatment prompted us to investigate the effects of this alkaloid on cell proliferation. Cell proliferation is a key trait of planarian regeneration and the post-traumatic inability of cells to proliferate results in a failure to generate the blastema at the wound site. Cell proliferation in sanguinarine-treated planarians and controls was compared by Western blot with the anti-phospho-histone H3 (H3P) antibody and analysis of the expression level of Dj-mcm2, a marker specific for proliferating stem cells (Salvetti et al., 2000) during different time points of regeneration ( 3 and 7 days). We observed that there is not significant variation in the proliferative response between sanguinarine-treated animals and controls (Fig. 5 A,B). Immunostaining and Western blot analysis with anti-DjPiwiA (Yoshida-Kashikawa et al., 2007) also demonstrated that the

Fig. 4. Sanguinarine treatment interferes with morphallactic remodelling of pre-existing tissues. (A) Regenerating planarian tail fragments visualized after whole mount in situ hybridization with the marker of the pharynx Dj-mhca in a control and in a sanguinarine-treated planarian after 7 days of treatment (regeneration: 7 days). Ventral view is shown to better visualize the pharynx. In most sanguinarine-treated tail fragments (53\%) the pharynx appeared oversized and anteriorly shifted with respect to the controls. (B) Morphometric analysis of pharynx size in sanguinarine-treated planarian fragments and controls after 7 days of treatment. Values are average $\pm s$. $d$. from 30 samples. ${ }^{*}: P<0,05$. (C) Intestine of regenerating planarian tail fragments visualized after whole mount in situ hybridization with Dj-inx 1 in a control and in a sanguinarine-treated planarian after 7 days of treatment (regeneration: 7 days). Most sanguinarine-treated planarians (66\%) showed abnormal morphogenesis of the intestine. (D) The graph shows the percentage of sanguinarine-treated animals and controls able to eat following 7 days of treatment. For each experiment, 30 animals were used. **: $P<0,01$. Control: DMSO 0,015\%; SANG: sanguinarine $0.15 \mu \mathrm{M}$. Anterior is up. Scale bar: $1 \mathrm{~mm}$. number of stem cells did not changed significantly (Fig. 5C). At 7 days of regeneration some differentiation-related genes were significantly upregulated as a consequence of the treatment: Dj-vas 1, a gene encoding an RNA helicase with a possible role in neoblast differentiation (Rouhana et al., 2010), Dj-nos, a gene essential for germline specification (Wang et al., 2007), Dj-nb21.11e, an early stem cell progeny marker and Dj-agat2, a late stem cell progeny marker (Eisenhoffer et al., 2008) (Fig. 5D). Taken together, these results suggest that sanguinarine alters cell dynamics promoting stem cell differentiation during a transition state in which cells are more susceptible to signals that can affect their gene expression.

\section{Sanguinarine perturbs the expression level of molecular markers specific for differentiated cells}

Possible effects of sanguinarine on differentiated cell types were evaluated by comparing the transcriptional profile of tissue-

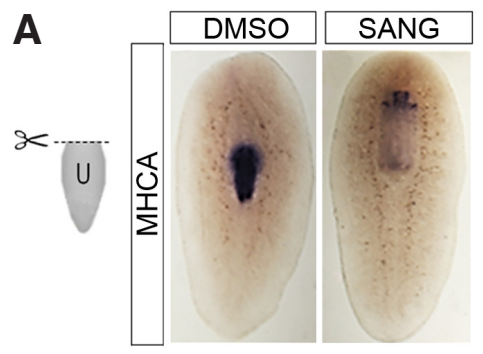

B
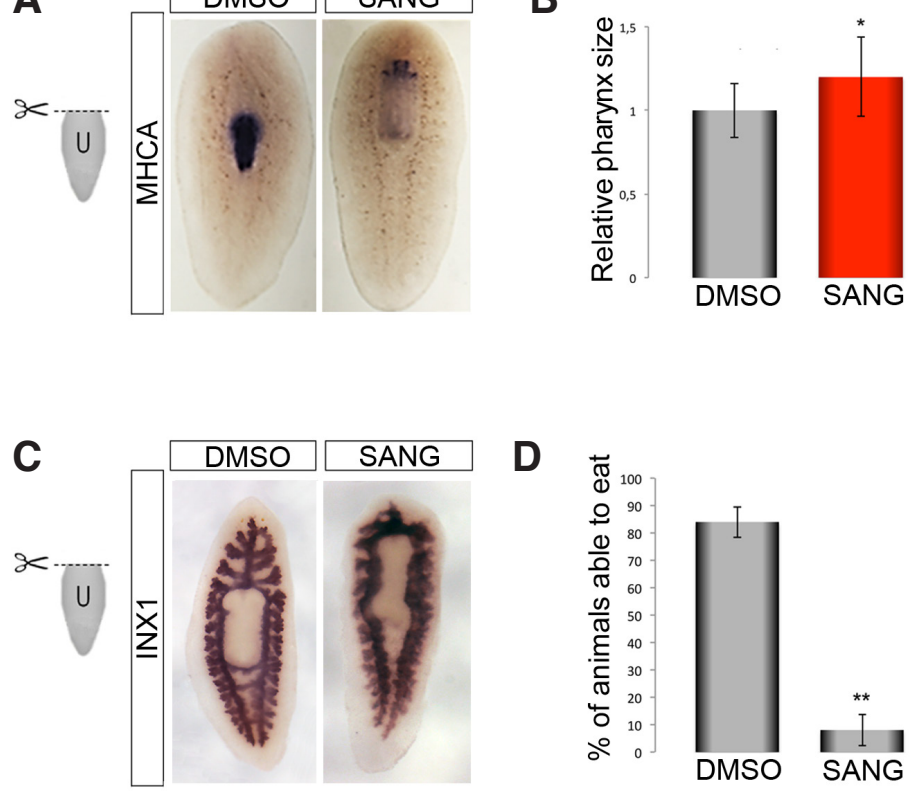
specific markers in sanguinarine-treated planarians and controls. The markers we used identify intestinal cells (Dj-inx1; Nogi and Levin, 2005), mesenchymal cells (Dj-mt-mmpa; Isolani et al., 2013), excretory cells (Dj-inx10; Nogi and Levin, 2005), adhesive marginal gland cells (Dj-ifb; Tazaki et al., 2002) and pharynx muscle cells (Dj-mhca; Kobayashi et al., 1998). Real time RT-PCR demonstrates that sanguinarine may differentially influence the expression level of tissue-specific genes. In fact, while expression level of Dj-ifb remained unchanged following exposure to the alkaloid, exposed planarians revealed significantly lower levels of $D j$-mhca mRNA with respect to the controls. Conversely, Dj-inx1, Dj-inx10 and Dj$m t-m m p a$ transcripts were upregulated by sanguinarine (Fig. 6).

\section{Effects of sanguinarine on apoptosis}

It is known that sanguinarine promotes apoptosis in tumor cell lines, but only few studies demonstrate in vivo apoptotic effects of sanguinarine (Chan, 2014). To investigate potential effects of the alkaloid on apoptosis we performed the caspase-3 assay on regenerating planarians. In concert with stem cell division, two dramatic peaks of apoptotic cell death characterize planarian regeneration at 4 hours and 3 days from amputation under physiological conditions (Pellettieri et al., 2010). For this reason, the analysis was performed in planarians sacrificed at 4 hours, 3 days and also at 7 days from amputation. The results show that sanguinarine induces significant increase in caspase-3 activity, implying that sanguinarine-treated animals have increased propensity to undergo apoptosis (Fig. 7A) Moreover, TUNEL assay showed that, according to what described in literature (Pellettieri et al., 2010), a massive systemic increase in apoptotic cells was detectable 3 days after amputation in regenerating animals. Despite this generalized increase, no significant differences with respect to controls were detected in sanguinarine-treated head fragments sacrificed 3 days after amputation. On the other hand, a significant higher number of apoptotic cells was detected in sanguinarine-

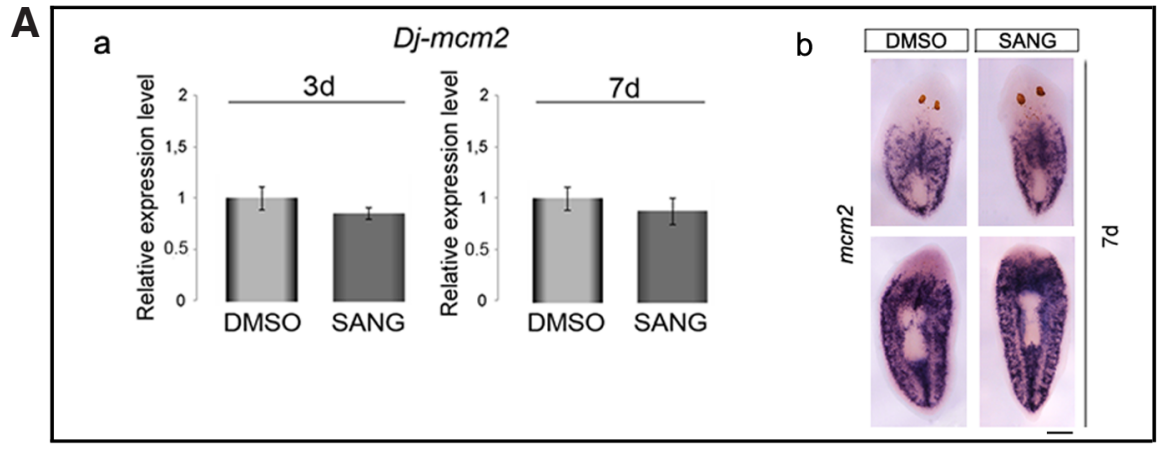

B

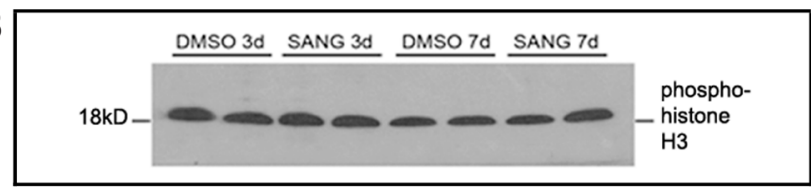

c
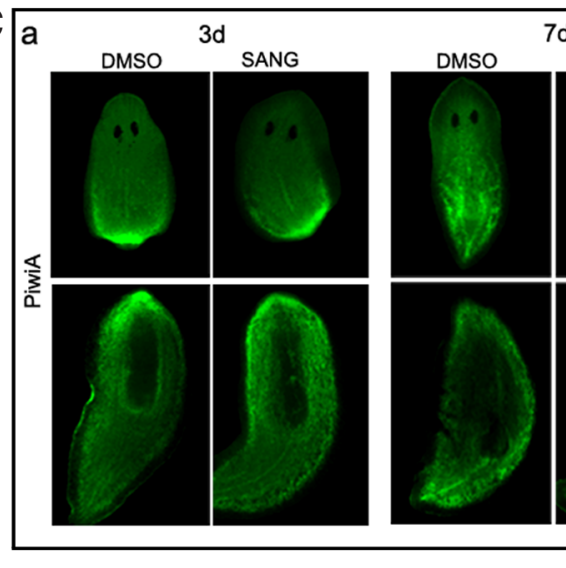

$7 d$
SANG
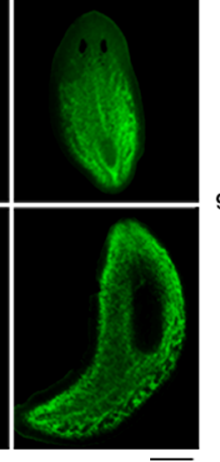

b

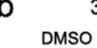

DMSO SANG

$93 \mathrm{kD}$
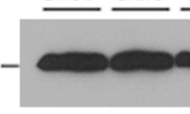

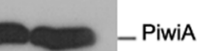

D
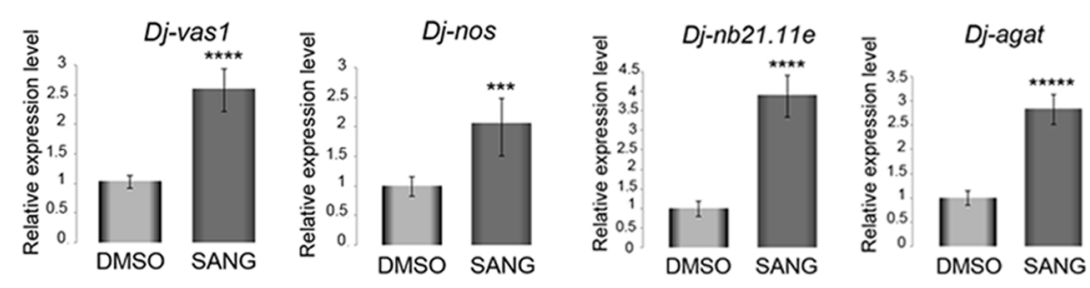

Fig. 5. Effects of sanguinarine on stem cells and their progeny. (A) Expression of Dj-mcm2 (a) Sanguinarinetreated planarian fragments and controls analyzed by real time RT PCR after 3 days and 7 days of treatment (regeneration: 3 and 7 days, respectively). No significant differences are detectable in the level of expression. (b) Visualization of representative phenotypes after whole mount in situ hybridization with Dj-mcm2 in a control and in a sanguinarine-treated fragment after 7 days of treatment (regeneration: 7 days). No significant differences are detectable in the expression pattern. (B) Western blotanalysis of H3P expression in sanguinarine-treated fragments and controls analyzed at 3 and 7 days of treatment (regeneration: 3 and 7 days, respectively). Two independent samples analysed for each condition are shown. (C) Visualization of representative phenotypes by immunostaining with Dj-PiwiA antibody. (a) sanguinarine-treated head and tail fragments and controls after 3 and 7 days of treatment (regeneration: 3 and 7 days, respectively); (b) Western blot analysis of Dj-PiwiA expression in sanguinarine-treated fragments and controls analyzed at 3 and 7 days of treatment (regeneration: 3 and 7 days, respectively). No significant differences are detectable in Dj-PiwiA expression between controls and sanguinarine-treated animals (D) Real Time RT-PCR analysis of the expression level of stem cell progeny markers (Dj-vas1, Dj-nos, Dj-nb21.11.e and Dj-agat) in sanguinarine-treated planarian fragments and controls analyzed after 7 days of treatment (regeneration: 7 days). In $A$ and $D$ the expression levels are indicated in relative units, assuming as unitary the value of the control. Each value is the mean \pm s.d. of 3 independent experiments, carried out in 6 replicates. ${ }^{* *}: P<0,001$; ****: $P<0,0001 ; * * * * *: P<0,00001$. For in situ hybridization and immunostaining experiments, 30 animals were used. Control: DMSO 0,015\%; SANG: sanguinarine 0.15 uM. d: days. Scale bar $1 \mathrm{~mm}$. 
treated tail fragment $(1242 \pm 240)$ with respect to controls $(793 \pm 39)$ (Fig. 7B). At 7 days from amputation, the number of apoptotic cells reduced to basal level in DMSO-treated fragments (Fig. 7B), while a significant increase $(P<0.01)$ of TUNEL-positive cells was detectable in both sanguinarine-treated head and tail fragments. In both types of fragments most of apoptotic cells were located in the anterior body region with a very consistent accumulation in the anterior blastema of tail fragments while only a few apoptosis were detectable in posterior blastema of head fragments (Fig. 7B). However the effects of sanguinarine on programmed cell death could not be confined to apoptosis. In fact the expression level of Dj-dap, a gene that has been implicated in autophagy in planarians (González-Estévez et al., 2007) appeared significantly increased by the treatment (data not shown).

\section{Sanguinarine affects the expression level of the planarian $\mathrm{H}^{+}, \mathrm{K}^{+}-$ATPase $\alpha$ subunit pump gene}

$\mathrm{H}^{+}, \mathrm{K}^{+}$-ATPase a subunit is the single non-gastric planarian member of the P-type ATPase pump family, whose pharmacologic or genetic perturbation alters head regeneration and tissue remodelling. Interestingly, the phenotypes obtained by the functional ablation of this gene (regenerates with tiny 'shrunken' heads and proportionally oversized pharynges: Beane et al., 2013) strongly resembled those obtained following sanguinarine treatment. In addition, literature data report interaction of sanguinarine with P-type pumps (Janovská et al., 2010). For these reasons we decided to analyze the effects produced by this alkaloid on the expression level of $H+, K+-A T^{P}$ ase $\alpha$ subunit in $D$. japonica. The results demonstrate that the treatment with sanguinarine significantly upregulates these transcripts (Fig. 8).

\section{Discussion}

Alkaloids derived from plant sources often exhibit significant biological activities that can have beneficial effects for human health. Several beneficial properties have been attributed to the natural alkaloid sanguinarine, including interesting anticancer effects and its use has become an attractive possibility in the treatment of several diseases. Consequently the toxicological aspects of this compound need to be carefully assessed, especially in vivo. In particular the evaluation of its effects on development may be crucial to prevent adverse effects in developing organisms. This study focuses on investigating the potential toxic effects of sanguinarine on development, with special emphasis on its effects on planarian regeneration. We have found that sanguinarine, administered by soaking at micromolar concentrations enters the body and shows remarkable effects in planarians. This observation correlates with the results shown in other model systems. It has been demonstrated that low doses $(0.25-2 \mu \mathrm{M})$ of sanguinarine may induce apoptotic response in several tumour cells, while higher concentrations $(25 \mu \mathrm{g} / \mathrm{ml})$ may cause oncosis (Gaziano et al., 2016). There are few studies on the in vivo effectiveness of sanguinarine in animal tumor models. Intraperitoneal administration $(2.5 \mathrm{mg} / \mathrm{kg}$ body weight) or administration per os $(60 \mathrm{mg} / \mathrm{kg} /$ day) of this compound produce complex physiological effects whose the molecular mechanisms are not fully understood. Administration of sanguinarine in planarians perturbs normal regeneration at very low concentrations. Sanguinarine-treated animals regenerated an anterior blastema that was reduced in size and anomalous in shape when compared to the controls, or did not regenerate at all. On the other hand, our observations reveal that tail regeneration was normally accomplished in all animals. The effects of sanguinarine treatment seem to be reversible. Complete recovery of the regeneration capabilities and body remodelling was in fact observed when sanguinarine-treated planarians underwent a second round of regeneration in planarian water. We do not know why sanguinarine selectively affects anterior regeneration. It is possible that the effect correlates with the dynamics of regeneration between the different body parts. On the other hand we cannot completely exclude the possibility that neuronal cell types are more sensitive to the effects of this alkaloid. This is consistent with the known effects of different toxicants on brain regeneration (Hagstrom et al., 2016). The most frequent anatomical anomalies seen during anterior regeneration included alterations of neural structures, i.e. cephalic ganglia and eyes that were partially or totally localized in the stump below the wound region. Studies in mammals provide evidence that the nervous system may be a preferential target of sanguinarine (Lee et al., 2001). Because anomalous/no regeneration or head regression in intact animals have been associated to impaired function of the neoblast population (Reddien et al., 2005) we first checked the proliferative response to amputation in sanguinarine-treated animals
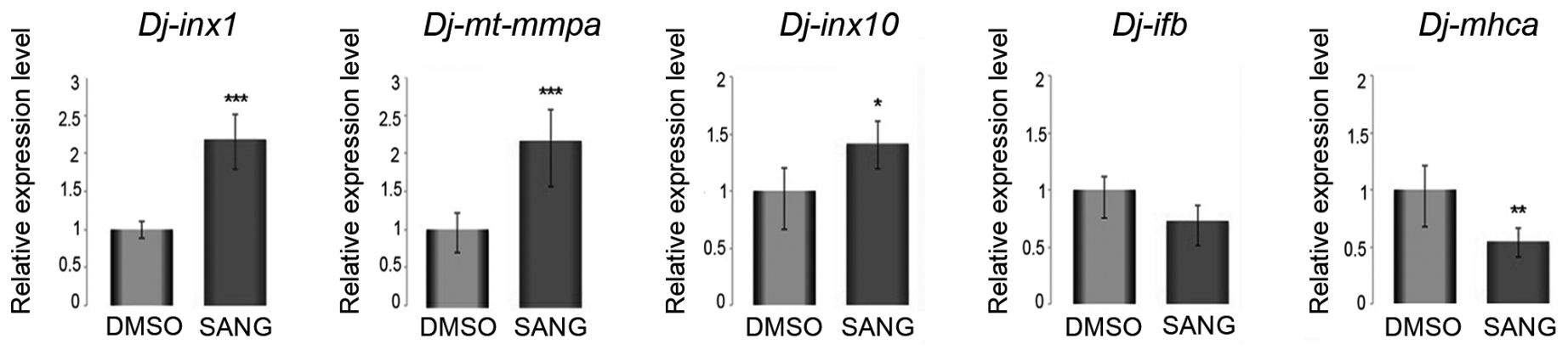

Fig. 6. Effects of sanguinarine on differentiated cell types. Relative expression level of representative markers of differentiated tissues: intestinal cells (Dj-inx1), mesenchymal cells (Dj-mt-mmpa), excretory cells (Dj-inx10), adhesive marginal gland cells (Dj-ifb) and pharynx muscle cells (Dj-mhca) in sanguinarine-treated planarian fragments and controls analyzed after 7 days of treatment (regeneration: 7 days). The expression levels are indicated in relative units, assuming as unitary the value of the control. Each value is the mean \pm s.d. of 3 independent experiments, carried out in 6 replicates. ${ }^{*}$ : $p<0,05 ;{ }^{* *}: p<0,01 ; * *: p<0,001$. Control: DMSO 0,015\%; SANG: sanguinarine $0.15 \mu \mathrm{M}$. 
A

B
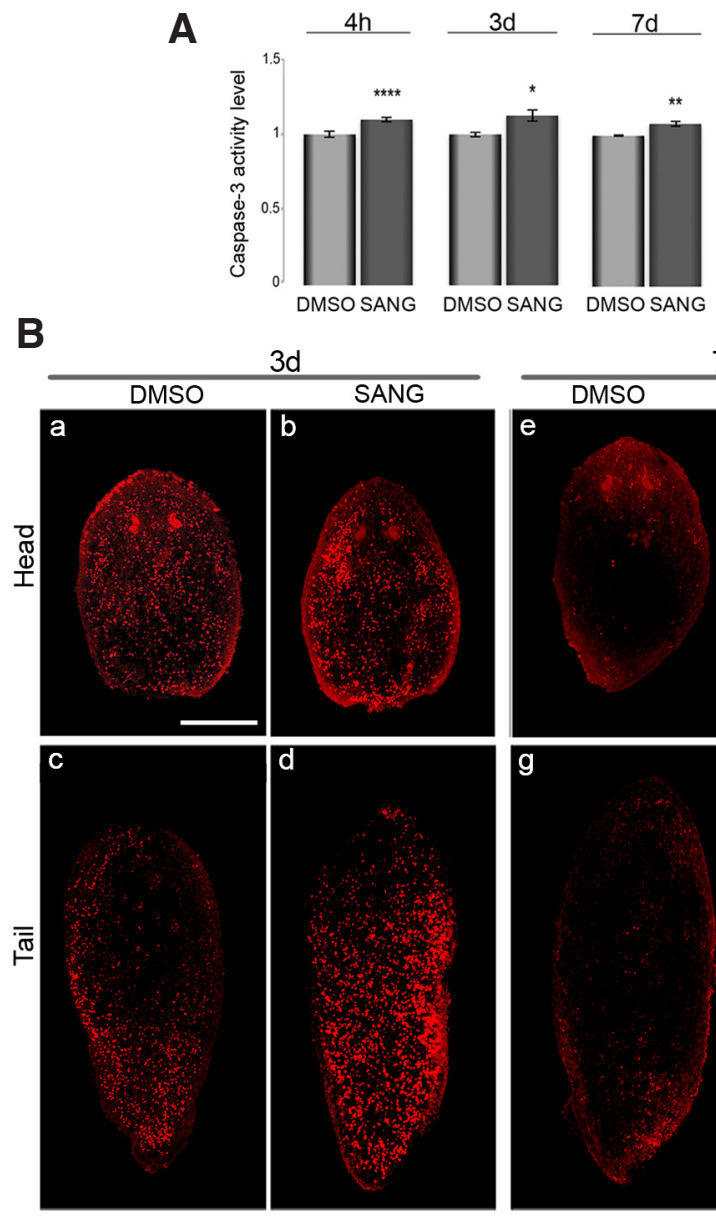

DMSO
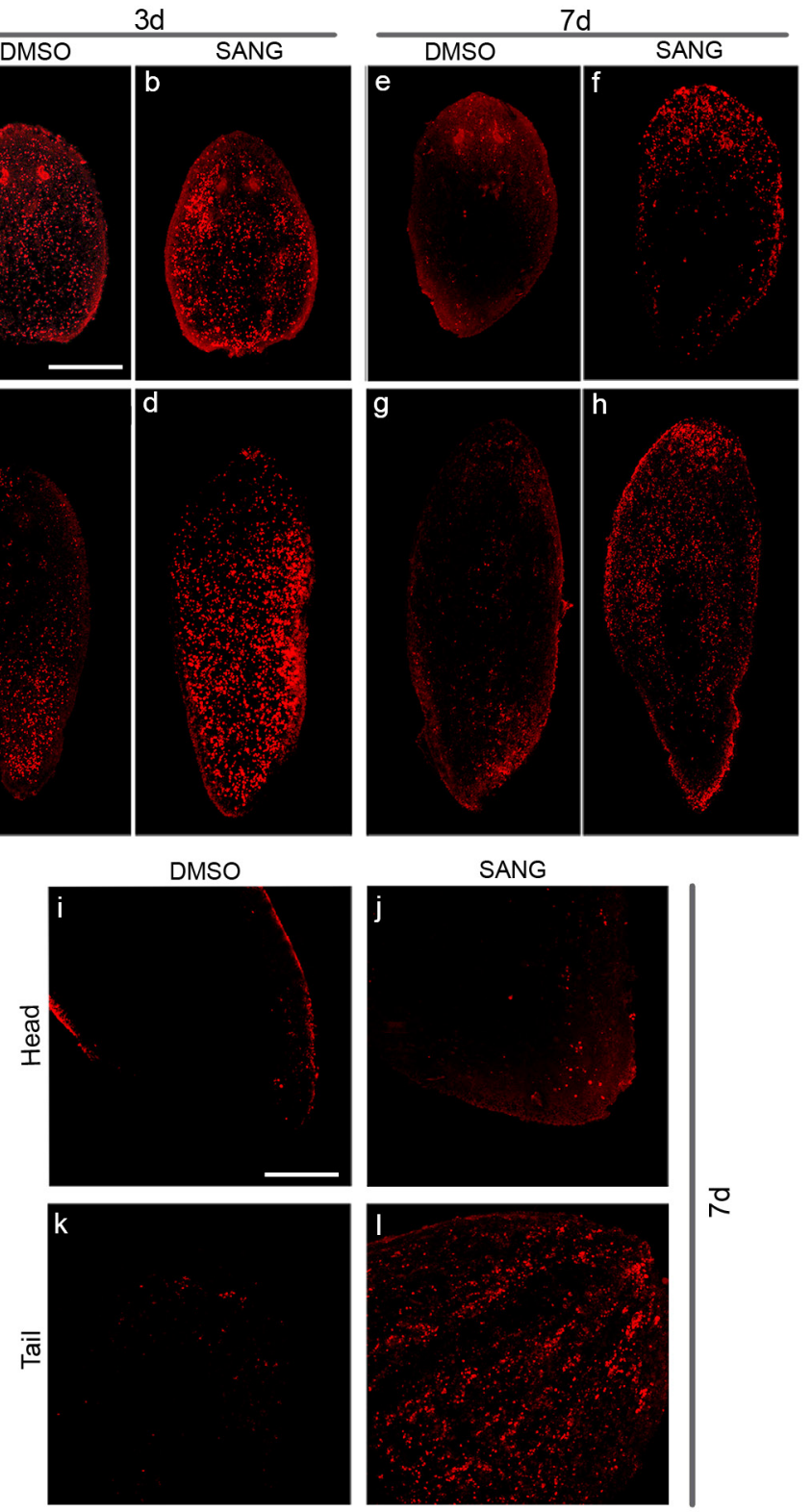

SANG
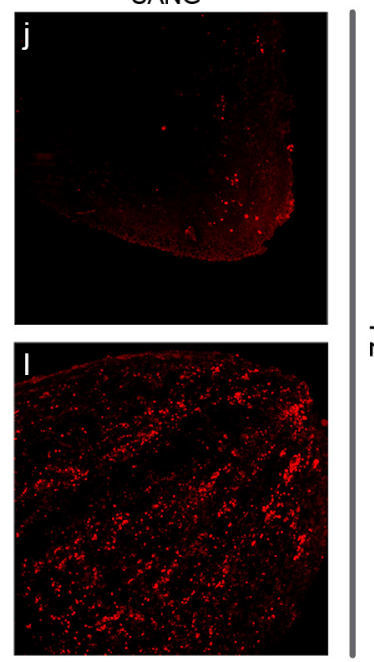

at different time points. Our data show that self-renewal and maintenance of neoblasts were not significantly influenced by the treatment. Sanguinarine is described in literature as an antiproliferative alkaloid (Gaziano et al., 2016), and its selective action against cancer cells is still subject to debate within medical research (Kaminskyy et al., 2008). This is a crucial matter in the development of an anticancer drug to characterize its safety profile. Western blot with the H3P antibody and the molecular marker Dj-mcm2
Fig. 7. Effects of sanguinarine on apoptosis. (A) Activation of caspase-3 in sanguinarine-treated planarians (SANG) and controls (DMSO) after 4 hours, 3 days and 7 days of treatment (regeneration: 4 hours, 3 and 7 days, respectively). Data represent mean values \pm s.d. from 3 independent samples. ${ }^{*}$ : $P<0,05 ;{ }^{*} ; P<0,01 ;{ }^{* * *} ; P<$ 0,0001 . (B) Tunel assay on regenerating head and tail fragments after 3 and 7 days in controls and sanguinarine-treated animals. $(a, b, c, d)$ : representative images of (a) control head fragment and (b) sanguinarinetreated head fragment, regenerating a posterior blastema 3 days after amputation; (c) a control tail fragment and (d) a sanguinarine-treated tail fragment regenerating an anterior blastema 3 days after amputation. $(e, f, g, h)$ : representative images of (e) a control head fragment and (f) a sanguinarine-treated head fragment regenerating a posterior blastema 7 days after amputation; (g) a control tail fragment and (h) a sanguinarine-treated tail fragment regenerating an anterior blastema 7 days after amputation. (i,j, $k$, l) Magnification of (i) blastema region of a control head fragment and (j) sanguinarine-treated head fragment, 7 days after amputation; ( $k$ ) blastema region of a control tail fragment and (I) sanguinarine-treated tail fragment, 7 days after amputation. At least 3 different fragments were analyzed for each experimental condition. d: days. Scale bar: $500 \mu \mathrm{m}$ for (a-h) and $180 \mu \mathrm{m}$ for (i-l).

demonstrated that cell proliferation was not affected by treatment with $0.15 \mu \mathrm{M}$ sanguinarine. Comparison between sanguinarine-treated planarians and controls clearly indicated that there is no significant variation in the proliferative response. These results support the intriguing possibility of a possible selective antiproliferative activity of this alkaloid on tumor cells, but not in normal cells. As a consequence of unaltered proliferative activity also the amount of stem cells appears to be very similar in sanguinarine treated animals and control. Although the planarian proliferative cell population was kept constant, upregulation of the expression of early and late progeny markers indicated that sanguinarine exposure might be affecting cell differentiation. It is known that, in planarians, proliferation, differentiation and death of differentiated cells function in concert to regulate regeneration and tissue homeostasis. Coordination of these processes is crucial to restore body proportions through remodelling of existing tissues (Pellettieri et al., 2010). Our results on caspase-3 activity and

\section{$D j-H^{+}, K^{+}-A T P a s e$}

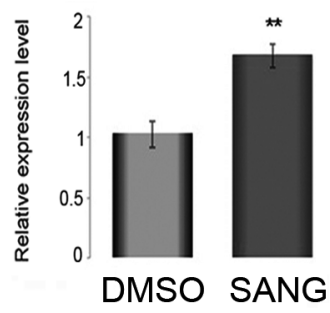

Fig. 8. Effects of sanguinarine on $\mathbf{D j}-\mathrm{H}+, \mathrm{K}+-$ ATPase $\alpha$ subunit. Relative expression level of $\mathrm{Dj}-\mathrm{H}^{+}, \mathrm{K}^{+}$- ATPase $\alpha$ subunit, analyzed by Real Time RT-PCR in sanguinarine-treated planarian fragments (SANG) and controls (DMSO) after 7 days of treatment (regeneration: 7 days). The expression levels are indicated in relative units, assuming as unitary the value of the controls. Each value is the mean \pm s.d. of 3 independent experiments, carried out in 6 replicates. **: $P<0,01$. Control: DMSO 0,015\%; SANG. sanguinarine $0.15 \mu \mathrm{M}$. 
TUNEL assay indicate significant induction of apoptosis in animals treated with sanguinarine compared to controls, suggesting the intriguing possibility that increased deletion of differentiated cells through apoptosis triggers asymmetric stem cell divisions, thus producing early and late progeny able to replace the lost differentiated cell types. This is consistent with the ability of sanguinarine to trigger alterations of components of the apoptotic machinery (Gaziano et al., 2016). However, our analyses also indicate that this alkaloid differentially influences cell replacement in different tissues, although we cannot say to what extent these assertions are generalizable. In fact, while expression level of $D j$-ifb (adhesive marginal gland cells) remained unaffected after sanguinarine treatment, the exposed planarians showed lower levels of Dj-mhca mRNA (pharynx muscle cells), increased expression of Dj-inx10 (excretory cells), Dj-mt-mmpa (mesenchymal cells) and Dj-inx1 (intestinal cells) with respect to the controls. Although no literature data are available in this context, it is possible that apoptosis affects some planarian tissues more than others or that diverse needs for homeostatic replacement influence the rate of cell death. This hypothesis needs to be analyzed in future studies. Although activation of apoptotic cell death is regarded as a dominant manner to eliminate cells, other mechanisms may modulate the steadystate cell population. Planarians survive to prolonged starvation or other stresses by autolysis, that is a type of non-apoptotic cell death with autophagic features, preferentially observed in cells of the intestine (González-Estévez et al., 2007). In sanguinarinetreated planarians the typical morphology of this tissue appeared damaged. This effect is probably due to sanguinarine accumulated in the gastrovascular cavity that may be toxic for gastrodermal cells. In eukaryotes, crosstalk between apoptosis and autophagic cell death has been described. An ortholog of mammalian DAP1, a negative regulator of autophagy that is thought to counteract autophagy from progressing to cell death, has been characterized in the planarian Girardia tigrina (Gt-dap1) (GonzálezEstévez et al., 2007), and is highly conserved in D. japonica. Gtdap1 is involved in autophagy and its expression is upregulated during stress-related events. Similarly, we observed upregulation of this gene in sanguinarine-exposed $D$. japonica, suggesting activation of a conserved damage response mechanism. Even $D j-m t-m m p a$ is upregulated following sanguinarine treatment. As transcriptional induction of this gene in stress conditions has been demonstrated (Isolani et al., 2013), it is possible that Dj-mt-mmpa upregulation in sanguinarine-treated animals represents a stress response to the alkaloid toxicity. Literature data show that sanguinarine modulates the activities of matrix metalloproteinases in tumor cell lines (Choi et al., 2009). Optimal activity of planarian matrix metalloproteinases appears critical in remodelling of ECM and its alteration results in a failure of neoblasts to migrate (Isolani et al., 2013). Our data support the possibility that the effects of sanguinarine on matrix metalloproteinases contribute to produce blastemas that appear reduced in size, as well as anomalous pharynx remodelling. However, it is important to bear in mind that sanguinarine is a compound with multitargeting properties and may affect diverse cellular/molecular processes with mechanisms of action that are only partially known (Gupta et al., 2010). Consequently, combination of different effects may promote in vivo the abnormalities we observed in planarians following sanguinarine exposure. Remarkably, we noted that sanguinarine- treated planarians showed phenotypes that strongly resemble those observed by the Beane's group following functional ablation of the $\mathrm{H}^{+}, \mathrm{K}^{+}$ATPase ion pump gene (Beane et al., 2011; Beane et al., 2013). Literature data show that the $\mathrm{Na}^{+} / \mathrm{K}^{+}$-ATPase pump is one of the targets of sanguinarine in the cell (Janovská et al., 2010). In planarians, the ion-pump function plays an important role during head regeneration and its manipulation causes multiple alterations of membrane potential that seem to be essential in head-versus-tail identity during regeneration. In particular it has been found that $\mathrm{H}^{+}, \mathrm{K}^{+}$-ATPase-mediated membrane depolarization is essential for the expression of anterior genes, brain induction and head formation (Beane et al., 2011; Beane et al., 2013). It is remarkable that the significant upregulation of the $\mathrm{Na}+/ \mathrm{K}+-\mathrm{ATP}$ ase ion pump gene, observed following sanguinarine treatment, induced phenotypes that were comparable to those obtained by its functional ablation by RNA interference. A possible explanation for this result is that any variation in the regulation of bioelectric signals influences cellular behaviour and the correct regulation of these signals is fundamental in determining anatomical polarity, shape and allometric organs scaling during planarian regeneration. However other mechanisms could be responsible for the phenotypes. Recent studies in planarians indicate that reactive oxygen species (ROS) play a key role in regulating neoblast differentiation and regeneration of the nervous structures (Pirotte et al., 2012). Remarkably it has been demonstrated that sanguinarine-induced apoptosis is associated with the generation of ROS in cancer cells (Kim et al., 2008). Further experiments are required to provide a mechanistic explanation of these effects.

\section{Conclusions}

To our knowledge the present study is the first reporting the effects produced by sanguinarine on planarian regeneration. Notably our model reveals that developmental dynamics, involving several critical determinants, are perturbed by this alkaloid. In summary, our results support the possibility that the biological responses observed following sanguinarine treatment involve multiple mechanisms, including cell differentiation and apoptosis. Although we cannot exclude that other mechanisms may be, directly or indirectly, responsible for the anomalous regeneration of the anterior structures, we suggest that this activity may be connected, at least in part, to alteration in the membrane polarization through regulation of different ATPase ion channels. These findings may have valuable implications to complement the outstanding questions raised about the safety profile of this alkaloid

\section{Materials and Methods}

\section{Animals and treatments}

$D$. japonica (clonal strain GI) was used as planarian model for all experiments. Planarians were maintained at $18^{\circ} \mathrm{C}$ in $1 \mathrm{x}$ planarian water $\left(2.5 \mathrm{mM} \mathrm{CaCl}_{2}, 0.4 \mathrm{mM} \mathrm{MgSO}_{4}, 0.8 \mathrm{mM} \mathrm{NaHCO}_{3}, 77 \mathrm{mM} \mathrm{KCl}\right)$ in a refrigerated incubator in the dark and fed with chicken liver once a week when not used for experiments. Test animals of $5 \mathrm{~mm}$ in length were selected from a population that had not been fed within 2 days. For each experiment, thirty intact animals were soaked in $30 \mathrm{ml}$ of solution and kept in plastic petri dishes. We synchronized the regeneration process pre-exposing for two hours the animals to sanguinarine before their amputation. Worms were bisected with a square coverslip (20 $\mathrm{mm}$ wide) at the prepharyngeal level and allowed to regenerate in the dark for 7 days. In an experiment the animals were transversely amputated at prepharyngeal and postpharyngeal 
Sanguinarine and planarian regeneration

level obtaining three pieces: head, trunk and tail. Lateral regenerants were obtained by longitudinal pharyngeal amputation. Animals were stored in the incubator and left to regenerate in the presence of each alkaloid dilution for 7 days in the dark. Control planarians were similarly exposed to the corresponding DMSO dilutions, as described by Isolani et al.,2012). $10 \mathrm{mM}$ stock solution of sanguinarine chloride $(\mathrm{C} 2 \mathrm{OH} 14 \mathrm{CINO} 4$, molecular weight 367.78, Sigma) was dissolved in dimethylsulfoxide (DMSO, Sigma). Working solutions were diluted in $1 \mathrm{x}$ planarian water just before each experiment. Control groups were represented by planarians soaked in corresponding DMSO dilutions. Solutions were made fresh and daily changed.

Toxicity profile of sanguinarine on regenerating planarians was analyzed. The animals were exposed for a week to different concentrations of sanguinarine $(0.1 \mu \mathrm{M} ; 0.15 \mu \mathrm{M} ; 0.2 \mu \mathrm{M} ; 0.3 \mu \mathrm{M} ; 0.4 \mu \mathrm{M} ; 0.5 \mu \mathrm{M} ; 0.7 \mu \mathrm{M}$; $0.9 \mu \mathrm{M} ; 1.1 \mu \mathrm{M})$. Controls were exposed to corresponding DMSO dilutions. For each condition, 3 independent experiments were performed with ten planarians of $5 \mathrm{~mm}$ in length. Worms were selected as described before, soaked in $15 \mathrm{ml}$ of the alkaloid solution after removing planarian water and bisected at the prepharyngeal level (2 hours after soaking). Worms that did not move even after gentle prodding or agitation of the water were considered dead. Deaths were manually annotated and overall data were tallied in Microsoft Excel. To investigate dose-response relationships linear regression analysis was used.

\section{RNA isolation, CDNA synthesis and real time RT-PCR}

Total RNA was isolated using the Eurogold total RNA kit (Euroclone), according to the manufacturer's instructions. Before cDNA synthesis, each extraction was tested for the absence of genomic DNA. cDNA was synthesized using QuantiTect ${ }^{\circledR}$ reverse transcription kit (Qiagen). For each experiment RNA extractions were performed with six independent experimental groups. Each RNA sample was obtained from an experimental group including 12 different regenerating fragments $(6$ head fragments +6 tail fragments). Real time RT-PCR was performed at least three times for each examined gene, using three replicates for each cDNA. SYBR Green chemistry-based RT-PCR was carried out on a Rotor-Gene 6000 Real time-PCR (Corbett Research) with GoTaq qPCR Master Mix (Promega). Details of the procedure are given in Supplementary Table S1, according to the MIQE guidelines. Preliminary experiments were performed to evaluate the transcriptional stability of candidate endogenous reference genes. The stability of six planarian endogenous reference genes, $D$. japonica elongation factor-2 (Dj-EF2), D. japonica b-actin (Dj-ACTB), D. japonica elongation factor-1 (Dj-EF1), D. japonica tubulin alpha chain (Dj-TUBA), D. japonica $18 S$ type I ribosomal RNA (Dj-18S), D. japonica glyceraldehyde 3-phosphate dehydrogenase (Dj-GAPDH) were analyzed using NormFinder software. Under our experimental conditions the most stable gene was $D j-T U B A$.

\section{In situhybridization and immunostaining}

Whole mount in situ hybridization and VC-1 immunostaining were performed as described in Balestrini et al., (2014) on sanguinarinetreated planarians and controls after 7 days of regeneration. DIG-labeled riboprobes were synthesized as previously described in Isolani et al., (2013). Immunostaining was performed with planarian anti-arrestin VC-1, a monoclonal antibody specific to the photoreceptors, diluted 1:2000 in antibody blocking solution. Alexa Fluor 488 (Molecular Probes) 1:1000 was used as secondary antibody. Whole mount images were captured using Nikon Eclipse Ti Inverted Microscope with Digital Sight Camera and NIS-Elements Microscope Imaging Software. Adobe Photoshop was used to orient, scale, and adjust images and improve clarity. For Dj-PiwiA immunostaining planarians were treated as for in situ hybridization up to the rehydration process. Rehydrated specimens were permeabilized with $20 \mu \mathrm{g} / \mathrm{ml}$ proteinase $\mathrm{K}$ for 6 minutes at $37^{\circ} \mathrm{C}$, post-fixed in $4 \%$ formaline and incubated overnight in the same mix used for in situ hybridization. Specimens were washed three times in TPBS3 (1x PBS plus $0,3 \%$ triton $X-100$ ) blocked in $10 \%$ fetal bovine serum diluted in TPBS1 (1X PBS plus $0,1 \%$ triton $\mathrm{X}-100)$ for 2 hours at room temperature and incubated with
1:100 dilution of mouse anti-Dj-PiwiA antibody (Yoshida-Kashikawa et al., 2007) over/night at $4^{\circ} \mathrm{C}$. After several washes in TPBS1 specimens were incubated in alexafluor 488 anti-mouse secondary antibody over/night at $4^{\circ} \mathrm{C}$. After extensive washing specimens were mounted in $80 \%$ glycerol. Whole mount images were captured using the Axioplan epifluorescent microscope (Zeiss).

\section{Analysis of caspase-3 activity and TUNEL assay}

Cell lysate proteins were obtained from 20 planarian fragments. Experiments were performed in sanguinarine-treated animals and in controls, in triplicate. The animals were washed in cold calcium, magnesium-free medium (CMF) and then chopped into small pieces, transferred into 250 $\mu \mathrm{l}$ of CMF plus papain $\left(30 \mathrm{U} / \mathrm{ml}\right.$, Sigma) for $1 \mathrm{~h}$ at $25^{\circ} \mathrm{C}$. The lysates were filtered in Nitex membrane (pore diameter $150 \mu \mathrm{m}$ ) and then added to the lysis buffer (Tris- $\mathrm{HCl} 20 \mathrm{mM} \mathrm{pH}$ 7.4, $150 \mathrm{mM} \mathrm{NaCl}, 1 \mathrm{mM}$ DTT, $5 \mathrm{mM}$ EDTA, $5 \mathrm{mM}$ EGTA, $0.1 \%$ TRITON X-100). Lysates were cleared by centrifugation at $1000 \mathrm{rpm}$ for $15 \mathrm{~min}$ at $4^{\circ} \mathrm{C}$. Protein content was determined by Bradford method, using the Bio-Rad protein assay kit (Bio-Rad Laboratories) and bovine serum albumin as a standard. Determination of caspase- 3 activity was carried out in a 96-well plate in a total volume of $50 \mu \mathrm{l}$. Extracts were incubated for $4 \mathrm{~h}$ in the presence of the corresponding tetrapeptide conjugated to paranitroaniline ( $\mathrm{pNA}$ ) and the released pNA was measured in a spectrophotometer (Ultra Microplate reader Bio-Tek Instruments Inc.) at $405 \mathrm{~nm}$ every 30 min using KC Junior software.

TUNEL assay was performed as described by Pellettieri et al., (2010) with a modification consisting in the pre-treatment of planarians with $2 \% \mathrm{HCl}$ / 5/8 Holtfreter solution instead of $\mathrm{N}$-acetylcysteine/PBS solution. Animals were mounted in $80 \%$ glycerol solution, and fluorescent signal was analyzed with a Leica confocal microscope by optical sectioning every $2 \mu \mathrm{m}$. At least 3 different fragments were analyzed for each experimental condition and the number of apoptotic cells was counted using the Image $\mathrm{J}$ software.

\section{Western blot analysis with $\mathrm{H} 3 \mathrm{P}$ and Dj-PiwiA antibody}

Proteins were obtained by homogenization of 4 planarians in lysis buffer as described above. Protein concentration was measured by Bradford method. Two independent samples were processed for each experimental condition. Twenty micrograms of proteins for each sample were separated by SDS-PAGE and electro-transferred onto a nitrocellulose membrane. Membrane was incubated with rabbit H3P antibody (UPSTATE) or mouse Dj-PiwiAantibody (Yoshida-Kashikawa et al., 2007), diluted 1:500 in 1\% skimmed milk. After incubation with a 1:16000 dilution of anti-rabbit or mouse peroxidase-conjugate secondary antibody (Biovision), detection was performed using Lumi-Light Western blotting Substrate reagents (Roche).

\section{Morphometric analysis}

The areas of the blastema and of the stump in sanguinarine-treated planarians and controls were determined as described in Balestrini et al., 2014. In brief, the animals were photographed at the same magnification with a stereomicroscope following ethanol-fixation, after 7 days of regeneration. The areas were measured using Nikon ACT-2U imaging software. A number of 30 regenerating fragments were analyzed for each experimental condition. The size of the pharynx after in situ hybridization with $D j-m h c a$ was measured with the same procedure.

\section{Statistics}

Data are expressed as mean \pm standard deviation (s.d.) of at least three independent experiments with three or six replicates. Data tabulation and descriptive statistics were performed with GraphPad Prism and Statgraphics (v. XVI) software. Normality was tested with Shapiro-Wilk and Kolmogorov-Smirnov test, and homoscedasticity was tested with F-test. Where necessary, the results were transformed to meet the requirements of normality and equal variance. Data were analyzed by Student's T-test and parametric ANOVA. Post hoc ANOVA Tukey's test was used when appropriate. $P$-value $\leq 0.05$ was considered statistically significant. 


\section{Acknowledgements}

This work was supported by grants from Pisa University, Italy. The Authors are also grateful to the International Society for Drug Development (ISDD), Milano, Italy for the financial support granted to a member of the research team.

\section{References}

ELLIOTT SA, SANCHEZ ALVARADO A. (2013). The history and enduring contributions of planarians to the study of animal regeneration. Wiley Interdiscip Rev Dev Biol. 2: 301-326.

BALESTRINI L, ISOLANI M E, PIETRA D, BORGHINI A, BIANUCCI A M, DERI P BATISTONI R (2014). Berberine exposure triggers developmental effects on planarian regeneration. Sci Rep 4: 4914.

BEANE W S, MOROKUMA J, ADAMS D S, LEVIN M (2011). A Chemical Genetics Approach Reveals H,K-ATPase-Mediated Membrane Voltage Is Required for Planarian Head Regeneration. Chem Biol 18: 77-89

BEANE W S, MOROKUMA J, LEMIRE J M, LEVIN M (2013). Bioelectric signaling regulates head and organ size during planarian regeneration. Development 140: 313-322.

CHAN W H (2014). Hazardous effects of sanguinarine on maturation of mouse oocytes, fertilization, and fetal development through apoptotic processes. Environ Toxicol 30: 946-955.

CHOI Y H, CHOI W Y, HONG S H, KIM S O, KIM G Y, LEE W H, YOO Y H (2009). Anti-invasive activity of sanguinarine through modulation of tight junctions and matrix metalloproteinase activities in MDA-MB-231 human breast carcinoma cells. Chem Biol Interact 179: 185-191.

EISENHOFFER G T, KANG H, SÁNCHEZ ALVARADO A (2008). Molecular analysis of stem cells and their descendants during cell turnover and regeneration in the planarian Schmidtea mediterranea. Cell Stem Cell 3: 327-339.

GAZIANO R, MORONI G, BUĖ C, MIELE MT, SINIBALDI-VALLEBONA P, PICA F. (2016). Antitumor effects of the benzophenanthridine alkaloid sanguinarine: Evidence and perspectives. World J Gastrointest Oncol 8: 30-39.

GONZÁLEZ-ESTÉVEZ C, FELIX DA, ABOOBAKER AA, SALÓ E (2007). Gtdap-1 promotes autophagy and is required for planarian remodeling during regeneration and starvation. Proc. Natl. Acad. Sci. USA 104: 13373-13378.

GUPTA S C, KIM J H, PRASAD S, AGGARWAL B B (2010). Regulation of survival, proliferation, invasion, angiogenesis, and metastasis of tumor cells through modulation of inflammatory pathways by nutraceuticals. Cancer Metastasis Rev 29: 405-434.

HAGSTROM D, COCHET-ESCARTIN O, COLLINS EM (2016). Planarian brain regeneration as a model system for developmental neurotoxicology. Regeneration 3: 65-77.

ISOLANI M E, ABRIL J F, SALÓ E, DERI P, BIANUCCI A M, BATISTONI R (2013). Planarians as a model to assess in vivo the role of matrix metalloproteinase genes during homeostasis and regeneration. PLoS One 8: e55649.

ISOLANI M E, PIETRA D, BALESTRINI L, BORGHINI A, DERI P, IMBRIANI M, BIANUCCI A M, BATISTONI R (2012). The in vivo effect of chelidonine on the stem cell system of planarians. Eur J Pharmacol 686: 1-7.

JANOVSKÁ M, KUBALA M, ŠIMÁNEK V, ULRICHOVÁ J (2010). Interaction of sanguinarine and its dihydroderivative with the $\mathrm{Na}+\mathrm{K}+-\mathrm{ATPase}$. Complex view on the old problem. Toxicol Lett. 196: 56-59.

KAMINSKYY V, LIN K W, FILYAKY, STOIKA R (2008). Differential effect of sanguinarine, chelerythrine and chelidonine on DNA damage and cell viability in primary mouse spleen cells and mouse leukemic cells. Cell Biol Int 32: 271-277.

KIM S, LEE T J, LEEM J, CHOI K S, PARK J W, KWON T K (2008). Sanguinarineinduced apoptosis: generation of ROS, down-regulation of Bcl-2, c-FLIP, and synergy with TRAIL. J Cell Biochem 104: 895-907.

KOBAYASHIC, KOBAYASHIS, ORII H, WATANABE K, AGATAK(1998). Identification of two distinct muscles in the planarian Dugesia japonica by their expression of myosing heavy chain genes. Zoolog Sci 15: 861-869.

KOSINA P, WALTEROVÁ D, ULRICHOVÁ J, LICHNOVSKÝ V, STIBOROVÁ M,
RÝDLOVÁ H, VICAR J, KRECMAN V, BRABEC MJ, SIMÁNEK V (2004). Sanguinarine and chelerythrine: assessment of safety on pigs in ninety days feeding experiment. Food Chem Toxicol 42: 85-91

LEE S S, KAI M, LEE M K (2001). Inhibitory effects of sanguinarine on monoamine oxidase activity in mouse brain. Phytother Res 2: 167-169.

MASCARENHAS A K, ALLEN C M, MOESCHBERGER M L (2002). The association between Viadent use and oral leukoplakia--results of a matched case-contro study. J Public Health Dent 62: 158-62.

NISHIMURA K, INOUE T, YOSHIMOTO K, TANIGUCHI T, KITAMURA Y, AGATA K (2011). Regeneration of dopaminergic neurons after 6-hydroxydopamine-induced lesion in planarian brain. $J$ Neurochem 119: 1217-1231.

NOGIT, LEVIN M (2005). Characterization of innexin gene expression and functional roles of gap-junctional communication in planarian regeneration. Dev Biol 287 314-335

PAGÁN OR, ROWLANDS AL, URBAN KR. (2006). Toxicity and behavioral effects of dimethylsulfoxide in planaria. Neurosci Lett. 407: 274-278.

PELLETTIERI J, FITZGERALD P, WATANABE S, MANCUSO J, GREEN D R SÁNCHEZ ALVARADO A (2010). Cell death and tissue remodeling in planarian regeneration. Dev Biol 338: 76-85.

PIROTTE N, STEVENS AS, FRAGUAS S, PLUSQUIN M, VAN ROTEN A, VAN BELLEGHEM F, PAESEN R, AMELOOT M, CEBRIÀ F, ARTOIS T, SMEETS K. (2015). Reactive Oxygen Species in Planarian Regeneration: An Upstream Necessity for Correct Patterning and Brain Formation. Oxid Med Cell Longev 2015: 392476-392495.

RAFFA R B and RAWLS S M (2008). Planaria: A Model for Drug Action and Abuse. Landes Bioscience.

REDDIEN P W, BERMANGE A L, MURFITT K J, JENNINGS J R, SÁNCHEZ ALVARADO A (2005). Identification of genes needed for regeneration, stem cell function, and tissue homeostasis by systematic gene perturbation in planaria. Dev Cell 8: 635-649.

ROUHANA L, SHIBATA N, NISHIMURA O, AGATA K (2010). Different requirements for conserved post-transcriptional regulators in planarian regeneration and stem cell maintenance. Dev Biol 341: 429-443

SALÓ E, ABRIL JF, ADELL T, CEBRIA F, ECKELT K, FERNANDEZ-TABOADA E. HANDBERG-THORSAGER M, IGLESIAS M, MOLINA MD, RODRÍGUEZESTEBAN G (2009). Planarian regeneration: achievements and future directions after 20 years of research. Int J Dev Biol, 53: 1317-1327.

SALVETTI A, ROSSI L, DERI P, BATISTONI R (2000). An MCM2-related gene is expressed in proliferating cells of intact and regenerating planarians. Dev Dyn 218: 603-614

STEVENS AS, PIROTTE N, PLUSQUIN M, WILLEMS M, NEYENS T, ARTOIS T, SMEETS K. (2015). Toxicity profiles and solvent-toxicant interference in the planarian Schmidtea mediterranea after dimethylsulfoxide (DMSO) exposure. $J$ Appl Toxicol. 35:319-326.

TAZAKI A, KATO K, ORII H, AGATAK, WATANABE K (2002). The body margin of the planarian Dugesia japonica: characterization by the expression of an intermediate filament gene. Dev Genes Evol 212: 365-373.

WANG Y, ZAYAS R M, GUO T, NEWMARK, P A (2007). Nanos function is essentia for development and regeneration of planarian germ cells. Proc Natl Acad Sci USA 104: 5901-5906.

YAO J Y, SHEN J Y, LI X L, XU Y, HAO G J, PAN X Y, WANG G X, YIN W L (2010). Effect of sanguinarine from the leaves of Macleaya cordata against Ichthyophthirius multifiliis in grass carp (Ctenopharyngodon idella). Parasitol Res 107: 1035-1042.

YOSHIDA-KASHIKAWA M, SHIBATA N, TAKECHI K and AGATAK (2007). DjCBC-1, a conserved DEAD box RNA helicase of the RCK/p54/Me31B family, is a component of RNA-protein complexes in planarian stem cells and neurons. Dev Dyn 236: 3436-3450

YUAN Z, ZHAO B, ZHANG Y.(2012) Effects of dimethylsulfoxide on behavior and antioxidant enzymes response of planarian Dugesia japonica. Toxicol Ind Health 28:449-457.

ZHANG S M, COULTAS K A (2013). Identification of plumbagin and sanguinarine as effective chemotherapeutic agents for treatment of schistosomiasis. Int $J$ Parasitoly: Drugs Drug Resist 3: 28-34. 


\section{Further Related Reading, published previously in the Int. J. Dev. Biol.}

Disto-proximal regional determination and intercalary regeneration in planarians, revealed by retinoic acid induced disruption of regeneration

R Romero and D Bueno

Int. J. Dev. Biol. (2001) 45: 669-673

http://dx.doi.org/10.1387/ijdb.11461003

Two $\mathrm{msh} / \mathrm{msx}$-related genes, Djmsh1 and Djmsh2, contribute to the early blastema growth during planarian head regeneration Linda Mannini, Paolo Deri, Vittorio Gremigni, Leonardo Rossi, Alessandra Salvetti and Renata Batistoni

Int. J. Dev. Biol. (2008) 52: 943-952

http://dx.doi.org/10.1387/ijdb.072476lm

Planarians in pharmacology: parthenolide is a specific behavioral antagonist of cocaine in the planarian Girardia tigrina

Oné R. Pagán, Debra Baker, Sean Deats, Erica Montgomery, Matthew Tenaglia, Clinita Randolph, Dharini Kotturu, Christopher Tallarida, Daniel Bach, Galia Wilk, Scott Rawls and Robert B. Raffa

Int. J. Dev. Biol. (2012) 56: 193-196

http://dx.doi.org/10.1387/ijdb.113486op

Physiological and molecular characterisation of cadmium stress in Schmidtea mediterranea

Michelle Plusquin, An-Sofie Stevens, Frank Van Belleghem, Olivier Degheselle, Andromeda Van Roten, Jessica Vroonen, Ronny Blust, Ann Cuypers, Tom Artois and Karen Smeets Int. J. Dev. Biol. (2012) 56: 183-191

http://dx.doi.org/10.1387/ijdb.113485mp

Inhibitory Smads and bone morphogenetic protein (BMP) modulate anterior photoreceptor cell number during planarian eye regeneration

Alejandro González-Sastre, Ma Dolores Molina and Emili Saló

Int. J. Dev. Biol. (2012) 56: 155-163

http://dx.doi.org/10.1387/ijdb.123494ag

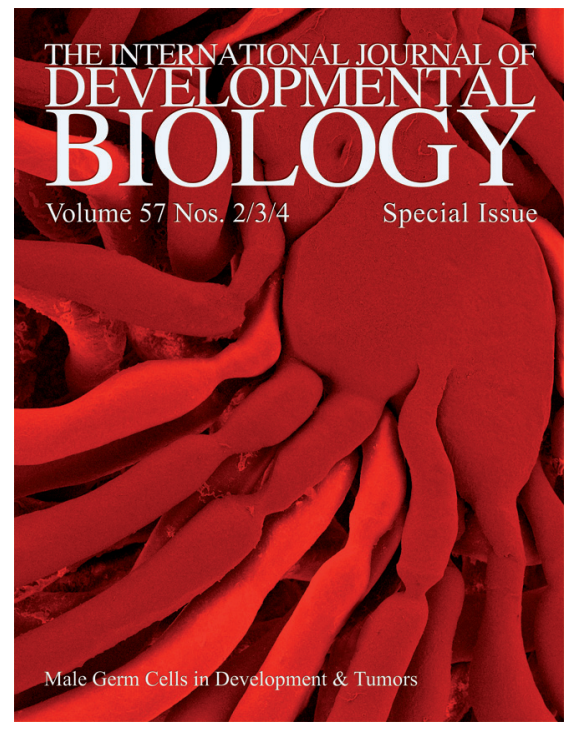

5 yr ISI Impact Factor $(2013)=2.879$
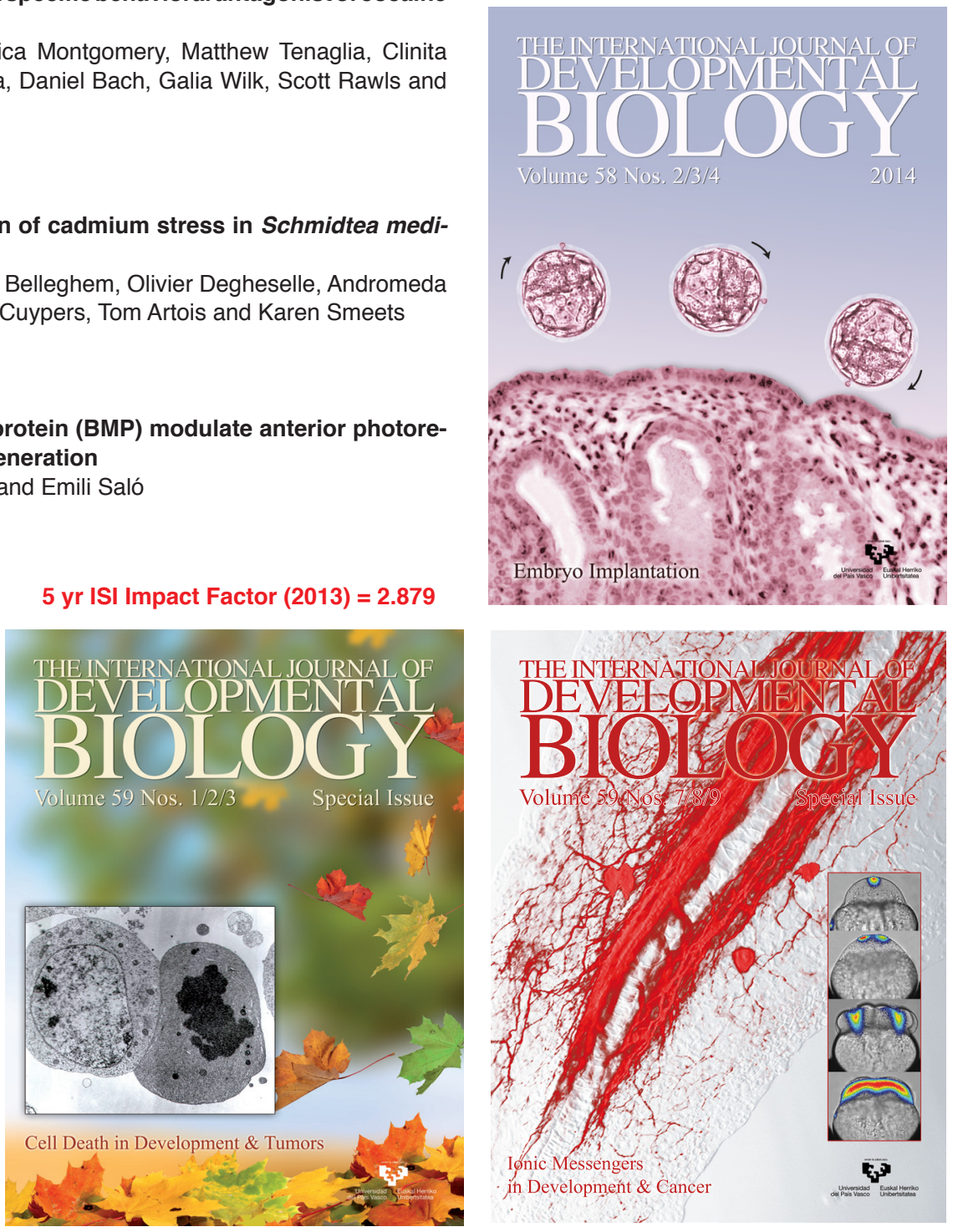